\title{
Evaluation of evening versus morning levothyroxine intake in elderly (MONIALE)
}

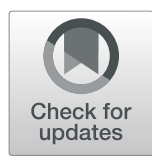

Karina Giassi ${ }^{1}$, Vanessa Piccoli ${ }^{2}$, Ticiana da Costa Rodrigues ${ }^{1,3}$ and Renato Gorga Bandeira de Mello ${ }^{1,2^{*}}$ (D)

\begin{abstract}
Background: The aging population is associated with increased multimorbidity and polypharmacy. Older adults are at a higher risk of adverse events and reduced therapeutic response. This phenomenon is partially explained by drug interactions and treatment adherence. Most randomized clinical trials have found no significant differences between morning and evening levothyroxine $\left(\mathrm{LT}_{4}\right)$ administration in young adults, but there is little evidence regarding alternative $\mathrm{LT}_{4}$ regimens in older populations. Thus, the MONIALE trial aims to test an alternative schedule for $\mathrm{LT}_{4}$ administration in older adults.

Methods/design: This randomized crossover clinical trial will include participants aged 60 years or older with primary hypothyroidism. The trial groups will consist of morning $\mathrm{LT}_{4}$ intake (60 min before breakfast) or evening $\mathrm{LT}_{4}$ intake (60 min after supper). The primary outcome will be variation in serum thyrotropin (TSH) levels after 24 weeks of the $\mathrm{LT}_{4}$ protocol. The secondary outcomes will be the prevalence of drugs that potentially interact with $\mathrm{LT}_{4}$ and hypothyroidism control according to interaction status. The sample size was calculated to detect a minimum mean difference of $1 \mathrm{mUI} / \mathrm{L}$ in serum TSH level between the groups with $80 \%$ power and a 5\% probability of type I error, resulting in 91 patients per group. The project was approved by the Hospital de Clínicas de Porto Alegre Ethics Committee.

Discussion: Considering the aging population, the increased prevalence of multimorbidity and polypharmacy, as well as potential drug interactions and treatment adherence difficulties, an alternative $\mathrm{LT}_{4}$ protocol could be useful for hypothyroidism treatment in the elderly. Prior studies comparing alternative LT4 administration protocols have mainly included young adult populations and have not addressed potential drug interactions.
\end{abstract}

Trial registration: ClinicalTrials.gov, NCT03614988. Registered 30 July 2018.

Keywords: Hypothyroidism, Aged, Levothyroxine

\section{Background}

Epidemiologic and demographic changes have resulted in aging of the population [1]. Between 1980 and 2017 the number of people aged 60 years or older worldwide has risen from 362 to 982 million, and by 2050 people in this age range will outnumber those in all other age ranges [2].

Older age is associated with a higher prevalence of multiple chronic diseases [3,4] and polypharmacy, which is generally defined in the literature as the use of five or

\footnotetext{
* Correspondence: rgmello@hcpa.edu.br

${ }^{1}$ Endocrinology Program, Universidade Federal do Rio Grande do Sul, Porto Alegre, Brazil

${ }^{2}$ Internal Medicine and Geriatric Division, Hospital de Clínicas de Porto

Alegre, Porto Alegre, Brazil

Full list of author information is available at the end of the article
}

more concomitant medications [5]. Adverse events, such as drug-drug interactions [6], non-adherence [7], suboptimal therapeutic effectiveness, and poor clinical response [8] are related to multiple drug use. Both multimorbidity and polypharmacy are correlated with falls, hospitalizations, functional limitations, and mortality $[9,10]$.

The prevalence of thyroid dysfunction increases with age $[11,12]$. The National Health and Nutrition Examination Survey, conducted between 1988 and 1994, found a hypothyroidism prevalence of $4.6 \%$ ( $0.3 \%$ clinical and $4.3 \%$ subclinical), being more common in women aged between 50 and 70 years $(p<0.001)$ [12]. Physiological changes due to the aging process could impact hypothyroidism treatment [13]. In older populations, pharmacokinetics might be modified by gastrointestinal

(c) The Author(s). 2019 Open Access This article is distributed under the terms of the Creative Commons Attribution 4.0 International License (http://creativecommons.org/licenses/by/4.0/), which permits unrestricted use, distribution, and 
aging and decreases in body water content, serum albumin, hepatic biotransformation, and renal clearance [14].

Levothyroxine is a synthetic derivative (levorotatory isomer) of thyroxine. Its ionization state and dissolution are influenced by gastric $\mathrm{pH}$ [15]. Although in healthy volunteers bioavailability can reach $60-80 \%[16,17]$, there could be a $9.4 \%$ decrease in thyroxine absorption in patients over 70 years old $(62.8 \% \pm 13.5 \%$ SD vs $69.3 \% \pm 11.9 \% ; p<0.001)$, as was found in a study of 45 euthyroid individuals [18]. The small bowel is the main site of absorption; the duodenum accounts for $15 \pm 5 \%$ $\mathrm{SD}$, the upper jejunoileum $29 \pm 14 \% \mathrm{SD}$, and the lower jejunoileum $24 \pm 11 \%$ SD of $24-\mathrm{h}{ }^{131}$ I-labeled thyroxine absorption [16]. The time necessary to reach the maximum serum concentration (Tmax) of the drug is approximately $2-3 \mathrm{~h}$ from ingestion, and plateaus occur at 18 and $48 \mathrm{~h}$. Food and hypothyroidism delay Tmax $[19,20]$.

Drug bioavailability is responsible for most inter- and intra-individual therapeutic variation [6], which can result from (a) nonadherence, (b) physiological (weight, pregnancy, age) and paraphysiological (behavior, nutrition) conditions, (c) malabsorption diseases, and (d) concomitant medications [8].

In an in vitro study, Pabla et al. found that a higher $\mathrm{pH}$ impairs dissolution of thyroxine [21], and Centanni et al. observed a higher thyroxine requirement in ten euthyroid patients with multinodular goiter who were receiving concomitant omeprazole [22]. In a prospective study, however, the hormone levels of 19 hypothyroid subjects did not change when they were advised to take omeprazole $30 \mathrm{~min}$ after $\mathrm{LT}_{4}$ [23]. Besides the known interaction with proton pump inhibitors, interactions between $\mathrm{LT}_{4}$ and other drugs/supplements have been recognized [24], such as with iron [25], calcium supplements [26], aluminum hydroxide [27], raloxifene [28], sevelamer [29], cholestyramine [30], and ciprofloxacin [31]. In light of these findings, the American Thyroid Association recommends a 4-h interval between potentially interfering drugs, although this is based on a low grade of evidence [32].

A survey of referral centers about the appropriate use of $\mathrm{LT}_{4}$ revealed that, although the majority of patients understood that $\mathrm{LT}_{4}$ should not be taken with food, only $52.1 \%$ were aware that it should also not be taken with other medications [33]. Forgetting to take the tablets and a lack of understanding about the need for continued treatment were found to be the causes of low adherence in two-thirds of 100 uncontrolled hypothyroidism patients [34].

In 1977, in a sample of healthy volunteers, Wenzel and Kirschsieper found that $\mathrm{LT}_{4}$ absorption decreased from $79.3 \% \pm 7.2 \%$ SD under fasting conditions to $63.9 \% \pm 10.5 \%$ SD after a meal of two buttered rolls and a boiled egg $(p<0.001)$ [17]. Years later, Bevenga et al. demonstrated that postponing breakfast from 15 to $20 \mathrm{~min}$ to $60 \mathrm{~min}$ improved the thyroid function tests in hypothyroid individuals [20]. $\mathrm{LT}_{4}$ has also been reported to interact with coffee [35], soy [36], grapefruit [37], and milk [38].

Although some prospective studies on the timing of $\mathrm{LT}_{4}$ administration have been published, they were not designed to include older adults. In a pilot study, Bolk et al. [39] assessed the TSH levels of 19 hypothyroid women (mean age 48 years) for $24 \mathrm{~h}$ on two separate days. Evening $\mathrm{LT}_{4}$ intake (hours after supper) lowered TSH levels more than morning intake $(30 \mathrm{~min}$ before breakfast) $(1.2 \pm 0.3 \mathrm{mUI} / \mathrm{L}$ vs $5.1 \pm 0.9 \mathrm{mUI} / \mathrm{L}, p<0.01)$. Despite the bedtime $\mathrm{LT}_{4}$ regimen, the circadian pattern of thyrotropin was maintained and did not interfere with morning blood sampling [39]. The same group was able to reproduce these results in a randomized crossover placebo-controlled trial with 90 hypothyroid patients (mean age 48 years), who were followed for 24 weeks. In the intergroup comparison, bedtime intake had a direct treatment effect, with a decrease in TSH levels of 1.25 $\mathrm{mIU} / \mathrm{L}$ (95\% confidence interval (CI) $0.60-1.89 \mathrm{mIU} / \mathrm{L}$; $p=0.001)$ and an increase in free $\mathrm{T} 4$ of $0.07 \mathrm{ng} / \mathrm{dL}(95 \%$ CI $0.02-0.13, p=0.01$ ) compared to intake $30 \mathrm{~min}$ before breakfast [40]. Rajput et al. [41] randomized 152 drug-naive hypothyroidism patients (mean age $34.30 \pm$ 11.82 years) into two parallel groups to receive $\mathrm{LT}_{4} 2 \mathrm{~h}$ after dinner or $30 \mathrm{~min}$ before breakfast. At the end of 12 weeks, finding no significant difference between treatment strategies for both euthyroidism (96\% vs 90\%; $p=0,19)$ and mean serum TSH levels $(3.27 \mathrm{mUI} / \mathrm{L} \pm$ 4.19 vs $5.13 \mathrm{mUI} / \mathrm{L} \pm 9.36 ; p=0.31$ ) [41]. Bach-Huynh et al. evaluated three timing strategies in 65 patients (48 \pm 13 years) and found that taking $\mathrm{LT}_{4}$ an hour before breakfast resulted in significantly lower TSH levels (1.06 $\mathrm{mIU} / \mathrm{L} 95 \%$ CI $0.60-1.52 \mathrm{mIU} / \mathrm{L} ; p<0.001)$ than when taking it $20 \mathrm{~min}$ before breakfast or $2 \mathrm{~h}$ after supper [42]. In agreement with these results, Perez et al. found higher serum TSH levels when $\mathrm{LT}_{4}$ was taken at the beginning of breakfast $(2.89 \mathrm{mIU} / \mathrm{L} \pm 2.82$ vs $1.9 \mathrm{mIU} / \mathrm{L} \pm 1.76$; $p=$ $0.028)$ than when taken $1 \mathrm{~h}$ before [43]. A recent study obtained data from 84 patients $(71 \%$ aged $\leq 65$ years old) on stable doses of $\mathrm{LT}_{4}$. They performed a three-period crossover trial of $\mathrm{LT}_{4}$ administration (30 $\mathrm{min}$ before breakfast, $1 \mathrm{~h}$ before lunch and $2 \mathrm{~h}$ after supper). No significant differences in thyroid profile results were found in the per-protocol analysis [44].

\section{Trial rationale}

Most published studies on the timing of $\mathrm{LT}_{4}$ administration have analyzed young populations and have not addressed the use of intervening medications. This trial aims to test an alternative schedule for $\mathrm{LT}_{4}$ administration in older adults with a randomized crossover clinical 
trial. Morning administration, which is more commonly used, will be compared with evening administration for 3 months of follow-up. This report follows the SPIRIT Statement guidelines [45]. We present a standardized checklist with recommended SPIRIT Statement items (Additional file 1).

\section{Methods/design}

\section{Study design and setting}

This prospective, randomized crossover trial will be conducted at the Endocrinology and Internal Medicine Clinic at the Hospital Clínicas de Porto Alegre, Brazil.

\section{Eligible participants}

The research team will identify outpatients $\geq 60$ years old with primary hypothyroidism who have been using $\mathrm{LT}_{4}$ for at least 6 months and have been on stable doses for the last 3 months. The study procedures will be explained to those who meet the inclusion criteria, and those who provide written informed consent will be enrolled. Screening will continue until the target population is achieved.

\section{Exclusion criteria}

The exclusion criteria are severe organic syndrome, dementia, thyroid cancer, heart failure (functional class IV), or three or more hospital admissions in the last year due to heart failure decompensation, and refusal to participate.

\section{Intervention}

Participants will be instructed to take $\mathrm{LT}_{4}$ tablets according to random treatment allocation, either in the evening (60 $\mathrm{min}$ after supper) or in the morning ( $60 \mathrm{~min}$

\section{MONIALE STUDY FLOWCHART}

\section{INCLUSION CRITERIA}

Hipothyroidism patient $\geq 60$ years old

Diagnosis of hypothyroidism $\geq 6$ months

Stable doses of levothyroxine $\geq 3$ months

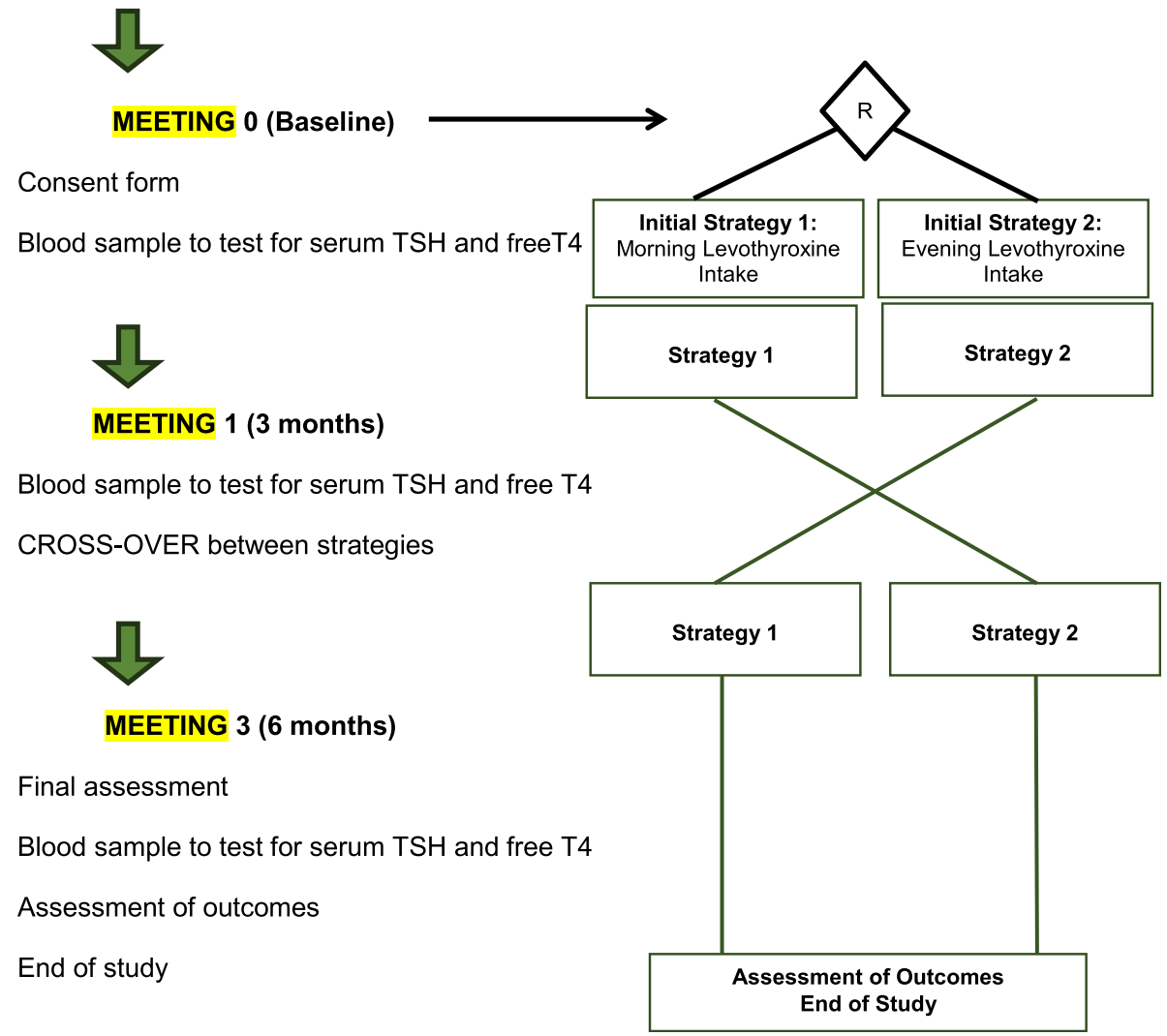

Fig. 1 Flow chart of the MONIALE trial: inclusion criteria, randomization, and follow-up process 
before breakfast). After 3 months of follow-up, the treatment will be changed using a crossover strategy.

\section{Outcomes}

Primary outcome

Change in serum TSH levels after 24 weeks of follow-up.

\section{Secondary outcomes}

1. To identify concomitant drugs that affect $\mathrm{LT}_{4}$ absorption

2. To compare TSH control efficacy between the two treatment strategies according to age, drug interaction, and sex subgroups

Sample size calculation

SAS Studio 3.7 was used to calculate the sample size. The calculated sample size (182 participants, 91 in each group) can detect a difference of $1.0 \mathrm{mUI} / \mathrm{L}$ between the means as significant, considering a standard deviation of 2.0 for group 1 and 3.87 for group 2 (BOLK, 2010). A power of $80 \%$ and significance level of $5 \%$ were considered in the calculation. Adding 10\% for possible losses and refusals, the sample size should be 200 .

\section{Random allocation}

A randomization list stratified by sex was created using a web-based program (http://www.randomization.com/). An interchangeable random blocks/variable blocks randomization strategy was chosen to assure allocation concealment. An independent researcher is responsible for the randomization list and treatment allocation.

\section{Blinding}

Due to the crossover design, the trial participants, staff, and outcome assessors will be not blinded, although data analysis will be blinded.

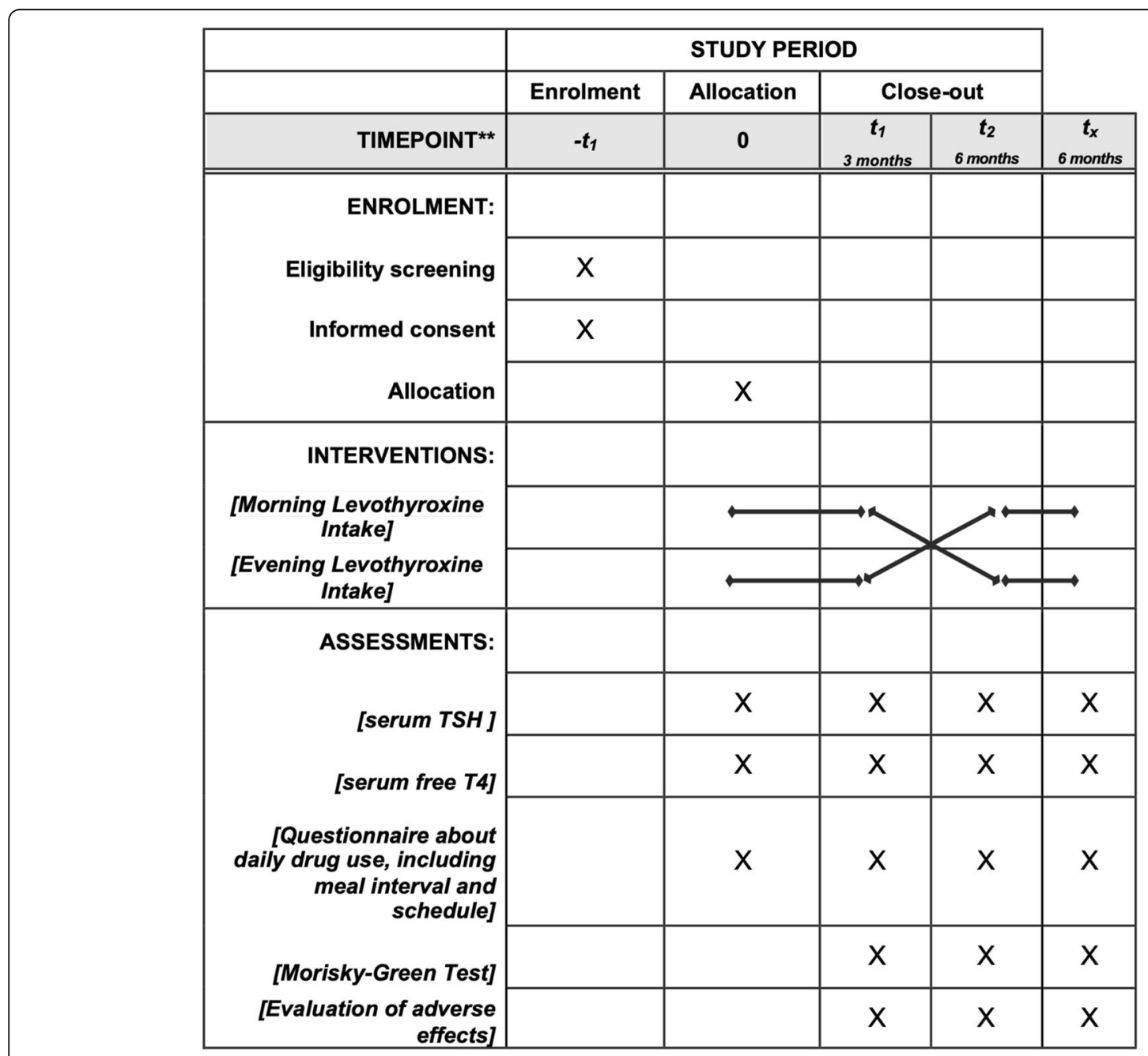

Fig. 2 SPIRIT figure: Allocation, interventions and outcomes 


\section{Data collection methods}

Eligible participants will attend meetings at 0,12 , and 24 weeks after enrollment. Each meeting will include application of standardized questionnaires to assess drug-food-thyroxine interactions, treatment adherence, and adverse events. Blood samples will be collected at baseline, 12 weeks, and 24 weeks after initial treatment allocation to measure free T4 and TSH levels. Figures 1 and 2 describe the follow-up procedure.

Thyroid function (serum TSH and free T4 levels) will be measured by electrochemiluminescence assay; concentrations of $0.27-4.2 \mathrm{mUI} / \mathrm{L}$ and $0.93-1.7 \mathrm{ng} / \mathrm{dL}$, respectively, are the method's reference limits. Food- $\mathrm{LT}_{4}$ interactions will be analyzed according to time since last meal (<30 min, 30-60 min, or $>60 \mathrm{~min}$ ). Concomitant use (within $60 \mathrm{~min}$ ) of calcium or iron supplements, proton pump inhibitors, other supplements/multivitamins, and daily medications will be considered in the drug$\mathrm{LT}_{4}$ interaction assessment. The Morisky-Green test will be used to verify treatment adherence and comprehension at baseline and follow-up. Side effects will also be investigated regarding causality between $\mathrm{LT}_{4}$ treatment and severity. Patients will be discontinued from the allocated intervention upon individual request or worsening of their clinical condition due to decompensated hypothyroidism.

\section{Statistical methods}

To assess the treatment effect, ANOVA for $2 \times 2$ crossover studies will be performed. The carryover effect will be analyzed by an independent samples $t$-test of the sum of the variables for each patient at 12 and 24 weeks [46]. No interim analysis is planned. Primary and secondary outcomes will be presented as intention-to-treat analysis. Additionally, subgroup analysis comparing age groups of $60-74$ years and $\geq 75$ years will be performed.

\section{Data monitoring and auditing}

No data monitoring committee will be created due to the single-blind treatment assignment and the short follow-up and interval between thyroid function tests. Although the study coordinator will constantly audit the data and study conduct, no external auditing process is planned.

Logistics procedures are presented in Fig. 1.

\section{Discussion}

Aging is associated with an increased prevalence of multimorbidity (defined as two or more long-term diseases) [4], including a higher frequency of hypothyroidism [12]. Disease-centered, rather than patient-centered, clinical practice guidelines have led to polypharmacy and related adverse events $[6,8]$. Due to these issues, in addition to pharmacokinetic changes, hypothyroidism treatment for older adults should be carefully managed [47].

Although alternative strategies of evening $\mathrm{LT}_{4}$ administration have been tested in clinical trials [39-44], the mean age of the included patients was under 60 years of age. In addition, most of the published trials have not addressed drug interaction [39-43] as a potential barrier to hypothyroidism control.

This study will evaluate the fastest growing population worldwide and will provide relevant clinical information for their medical care.

\section{Trial status}

Protocol version date 01/19/2018, Institutional Review Board number 2018-0209. This study is currently recruiting participants. The recruitment began in May 2018 and is expected to end by November 2019.

\section{Supplementary information}

Supplementary information accompanies this paper at https://doi.org/10. 1186/s13063-019-3816-3.

Additional file 1. SPIRIT 2013 checklist: Recommended items to address in a clinical trial protocol and related documents.

\section{Abbreviations}

ICMJE: International Committee of Medical Journal Editors;

$\mathrm{LT}_{4}$ : Levothyroxine; Tmax: Time until maximum serum concentration; TSH: Thyrotropin

\section{Acknowledgements}

The authors would like to thank the Internal Medicine and Endocrinology divisions of the Hospital de Clínicas de Porto Alegre, as well as the Federal University of Rio Grande do Sul Endocrinology Program for supporting clinical research, particularly this study.

\section{Grants}

The authors received grants from the Brazilian Ministry of Health, Division of Science and Technology (DECIT), and the Ministry of Science and Technology, FINEP, and CNPq.

\section{Authors' contributions}

KG: data collection, analysis, and manuscript writing. VP: data collection, manuscript writing, and manuscript revision. RGMB: study design, manuscript writing, revision, and final approval of the manuscript. TCR: study design, manuscript writing, revision, and final approval of the manuscript. All persons listed as authors have prepared and approved the manuscript and the ICMJE criteria for authorship have been met.

\section{Funding}

This project is being funded by the Hospital de Clínicas de Porto Alegre Fundo de Incentivo à Pesquisa and Eventos (FIPE). FIPE had no role in the study design, the data collection, analysis or interpretation, drafting the manuscript, or the decision to submit it for publication.

\section{Availability of data and materials}

The applied questionnaires will be stored at the research office with coded identification. The study data will remain unidentified. The final dataset will only be handled by the lead investigator, and the funding institution will not have access to it. The results of this clinical trial will be submitted to a peerreviewed medical journal following the authorship guidelines of the ICMJE CONSORT Statement. Following study publication, the unidentified dataset will be made available by the corresponding author upon formal request. 


\section{Ethics approval and consent to participate}

This project was approved by the Hospital de Clínicas de Porto Alegre Ethics Committee (83639318.2.0000.5327), which is accredited by the Office of Human Research Protection as an Institutional Review Board. Throughout the study, the local Ethics Committee will be notified of and will evaluate any protocol amendments. Informed consent will be obtained from all study participants.

\section{Consent for publication}

According to project number 83639318.2.0000.5327 of the Hospital de Clínicas de Porto Alegre Ethics Committee, written informed consent will be obtained from all individuals before participation in the study.

\section{Competing interests}

The authors declare that they have no competing interests.

\section{Author details}

'Endocrinology Program, Universidade Federal do Rio Grande do Sul, Porto Alegre, Brazil. ${ }^{2}$ Internal Medicine and Geriatric Division, Hospital de Clínicas de Porto Alegre, Porto Alegre, Brazil. ${ }^{3}$ Endocrine Division, Hospital de Clínicas de Porto Alegre, Rua Ramiro Barcelos, 2350, $4^{\circ}$ andar, Porto Alegre, RS CEP 90035-903, Brazil.

Received: 13 May 2019 Accepted: 22 October 2019

\section{Published online: 17 December 2019}

\section{References}

1. World Health Organization (2015). World report on ageing and health

2. United Nations, Department of Economic and Social Affairs, Population Division (2017). World population ageing 2017 - highlights (ST/ESA/SER. A/397).

3. Hajat C, Stein E. The global burden of multiple chronic conditions: A narrative review. Prev Med Rep. 2018;12:284-93. https://doi.org/10.1016/j. pmedr.2018.10.008.

4. Farmer $\mathrm{C}$, et al. Clinical assessment and management of multimorbidity: summary of NICE guidance. BMJ. 2016;354:1-23. https://doi.org/10.1136/bmj. i4843.

5. Masnoon $\mathrm{N}$, et al. What is polypharmacy? A systematic review of definitions. BMC Geriatr. 2017;17(1):1-10. https://doi.org/10.1186/s12877-017-0621-2 Springer Nature.

6. Maher RL, Hanlon J, Hajjar ER. Clinical consequences of polypharmacy in elderly. Expert Opin Drug Saf. 2014;13:57-65.

7. Zelko E, Klemencketis Z, Tusekbunc K. Medication adherence in elderly with polypharmacy living at home: a systematic review of existing studies. Mater Sociomed. 2016;28(2):129-32. https://doi.org/10.5455/msm.2016.28.129-132 ScopeMed International Medical Journal Management and Indexing System.

8. World Health Organization Multimorbidity. Technical series on safer primary care. Geneva; 2016. https://doi.org/10.1517/14740338.2013.827660. Licence: CC BY-NC-SA 3.0 IGO

9. Yarnall AJ, et al. New horizons in multimorbidity in older adults. Age Ageing. 2017:46(6):882-8. https://doi.org/10.1093/ageing/afx150 Oxford University Press (OUP).

10. Charlesworth CJ, et al. Polypharmacy among adults aged 65 years and older in the United States: 1988-2010. J Gerontol A Biol Sci Med Sci. 2015;70(8):989-95. https://doi.org/10.1093/gerona/glv013 Oxford University Press (OUP).

11. Canaris GJ, et al. The Colorado thyroid disease prevalence study. Arch Intern Med. 2000;160(4):526-34. https://doi.org/10.1001/archinte.160.4.526 American Medical Association (AMA).

12. Hollowell JG, et al. Serum TSH, T4, and thyroid antibodies in the United States population (1988 to 1994): National Health and Nutrition Examination Survey (NHANES III). J Clin Endocrinol Metab. 2002;87(2):489-99. https://doi. org/10.1210/jcem.87.2.8182 The Endocrine Society.

13. Chaker $L$, et al. Clinical aspects of thyroid function during ageing. Lancet Diabetes Endocrinol. 2018;6(9):733-42. https://doi.org/10.1016/ S22138587(18)30028-7 Elsevier BV.

14. Vrdoljak D, Borovac JA. Medication in the elderly - considerations and therapy prescription guidelines. Acta Med Acad. 2015;2(44):159-68. https:// doi.org/10.5644/ama2006-124.142.

15. Janiro G, Mangiola F, diRienzo TA. Levothyroxine absorption in health and disease, and new therapeutic perspectives. European review for hypothyroidism. J Thyroid Res. 2011;2011:1-5 Hindawi Publishing Corporation.

16. Hays MT. Localization of human thyroxine absorption. Thyroid. 1991;1:241-8.

17. Wenzel KW, Kirschsieper HE. Aspects of the absorption of oral L-thyroxine in normal man. Metabolism. 1977;26(1):1-8. https://doi.org/10.1016/00260495(77)90121-4 Elsevier BV.

18. Hays MT, Nielsen KR. Human thyroxine absorption: age effects and methodological analyses. Thyroid. 1994;4(1):55-64. Mary Ann Liebert Inc. https://doi.org/10.1089/thy.1994.4.55.

19. Berg JA, Mayor GH. A study in normal human volunteers to compare the rate and extent of levothyroxine absorption from Synthroid ${ }^{\oplus}$ and Levoxine ${ }^{\oplus}$ J Clin Pharmacol. 1992;32(12):1135-40 Lincolnshire.

20. Benvenga $S$, et al. Delayed intestinal absorption of levothyroxine. Thyroid. 1995;5(4):249-53. https://doi.org/10.1089/thy.1995.5.249 Mary Ann Liebert Inc.

21. Pabla D, Akhlaghi F, Zia H. A comparative pH-dissolution profile study of selected commercial levothyroxine products using inductively coupled plasma mass spectrometry. Eur J Pharm Biopharm. 2009;72(1):105-10. Elsevier BV. https://doi.org/10.1016/j.ejpb.2008.10.008.

22. Centanni M, Gargano L, Canettieri G, Viceconti N, Franchi A, Delle Fave G, Annibale B. Thyroxine in goiter, Helicobacter pylori infection, and chronic gastritis. N Engl J Med. 2006;354:1787-95. https://doi.org/10.1056/ NEJMoa043903

23. Abi-Abib RC, Vaisman M. Is it necessary to increase the dose of levothyroxine in patients with hypothyroidism who use omeprazole? Arq Bras Endocrinol Metabol. 2014;58(7):731-6. https://doi.org/10.1590/00042730000002997 Fap UNIFESP (SciELO).

24. Hennessey JV. The emergence of levothyroxine as a treatment for hypothyroidism. Endocrine. 2016;55(1):6-18. https://doi.org/10.1007/s12020016-1199-8 Springer Nature.

25. Campbell NR, Hasinoff BB, Stalts $H$, et al. Ferrous sulfate reduces thyroxine efficacy in patients with hypothyroidism. Ann Intern Med. 1992;117:1010-3. https://doi.org/10.7326/0003-4819-117-12-1010.

26. Zamfirescu I, Carlson HE. Absorption of levothyroxine when coadministered with various calcium formulations. Thyroid. 2011;21:483-6. https://doi.org/ 10.1089/thy.2010.0296.

27. Sperber AD, Liel Y. Evidence for interference with the intestinal absorption of levothyroxine sodium by aluminum hydroxide. Arch Intern Med. 1992; 152:183-4. https://doi.org/10.1001/archinte.1992.00400130181024.

28. Siraj ES, Gupta MK, Reddy SS. Raloxifene causing malabsorption of levothyroxine. Arch Intern Med. 2003;163:1367-70. https://doi.org/10.1001/ archinte.163.11.1367.

29. John-Kalarickal J, Pearlman G, Carlson HE. New medications which decrease levothryroxineabsorption. Thyroid. 2007;17:763-5. https://doi.org/10.1089/ thy. 2007.0060

30. Northcutt RC, Stiel JN, Hollifield JW, Stant EG. The influence of cholestyramine on thyroxine absorption. JAMA. 1969;208:1857-61. https:// doi.org/10.1001/jama.1969.03160100047012.

31. Goldberg AS, Tirona RG, Asher $L$, et al. Ciprofloxacin and rifampin have opposite effects on levothtroxine absorption. Thyroid. 2013;23:1374-8. https://doi.org/10.1089/thy.2013.0014.

32. Jonklaas J, et al. Guidelines for the treatment of hypothyroidism: prepared by the American Thyroid Association Task Force on Thyroid Hormone Replacement. Thyroid. 2014;24(12):1670-751. https://doi.org/10.1089/thy. 2014.0028 Mary Ann Liebert Inc.

33. Vaisman F, et al. How good is the levothyroxine replacement in primary hypothyroidism patients in Brazil? Data of a multicentre study. J Endocrinol Invest. 2013;36(7):485-8. https://doi.org/10.3275/8810 Editrice Kurtis srl.

34. Bagattoli RM, Vaisman M, Lima JS, Ward LS. Estudo de Adesão ao Tratamento do Hipotiroidismo. Arq Braz Endocrinol Metab. 2000:44(2):483-7.

35. Benvenga S, Bartolone L, Pappalardo MA, et al. Altered intestinal absorption of L-thyroxine caused by coffee. Thyroid. 2008;18:293-301. https://doi.org/ 10.1089/thy.2007.0222

36. Conrad SC, Chiu H, Silverman BL. Soy formula complicates management of congenital hypothyroidism. Arch Dis Child. 2004;89:37-40. https://doi.org/10. 1136/adc.2002.009365

37. Lilja JJ, Laitinen K, Neuvonen PJ. Effects of grapefruit juice on the absorption of levothyroxine. Br J Clin Pharmacol. 2005;60:337-41. https://doi.org/10. 1111/j.1365-2125.2005.02433.x.

38. Chon DA, et al. Concurrent milk ingestion decreases absorption of levothyroxine. Thyroid. 2018;28(4):454-7. https://doi.org/10.1089/thy.2017. 0428 Mary Ann Liebert Inc. 
39. Bolk $\mathrm{N}$, et al. Effects of evening vs morning thyroxine ingestion on serum thyroid hormone profiles in hypothyroid patients. Clin Endocrinol. 2006:438. https://doi.org/10.1111/j.1365-2265.2006.02681.x Wiley.

40. Bolk N. Effects of evening vs morning levothyroxine intake. Arch Intern Med. 2010;170(22):1996-2003. https://doi.org/10.1001/archinternmed.2010.436 American Medical Association (AMA).

41. Rajput R, Chatterjee S, Rajput M. Can levothyroxine be taken as evening dose? Comparative evaluation of morning vs. evening dose of levothyroxine in treatment of hypothyroidism. J Thyroid Res. 2011;2011:1-5. https://doi.org/10.4061/2011/505239 Hindawi Limited.

42. Bach-Huynh T-g, et al. Timing of levothyroxine administration affects serum thyrotropin concentration. J Clin Endocrinol Metab. 2009;94(10):3905-12. https://doi.org/10.1210/jc.2009-0860 The Endocrine Society.

43. Perez CLS, et al. Serum thyrotropin levels following levothyroxine administration at breakfast. Thyroid. 2013;23(7):779-84. https://doi.org/10 1089/thy.2012.0435 Mary Ann Liebert Inc.

44. Skelin $\mathrm{M}$, et al. Effect of timing of levothyroxine administration on the treatment of hypothyroidism: a three-period crossover randomized study. Endocrine. 2018;62(2):432-9. https://doi.org/10.1007/s12020-018-1686-1 Springer Nature America, Inc.

45. Chan AW, et al. SPIRIT 2013 Statement: Defining Standard Protocol Items for Clinical Trials. Ann Int Med. 2013;158(3):200-15. https://doi.org/10.7326/00034819-158-3-201302050-00583

46. Senn S. Cross-over trials in clinical research. 2nd ed. London: Wiley; 2002

47. Colucci P, et al. A review of the pharmacokinetics of levothyroxine for the treatment of hypothyroidism. Eur Endocrinol. 2010;9(1):40-7. https://doi.org/ 10.17925/ee.2013.09.01.40 Touch Medical Media, Ltd.

\section{Publisher's Note}

Springer Nature remains neutral with regard to jurisdictional claims in published maps and institutional affiliations.

Ready to submit your research? Choose BMC and benefit from:

- fast, convenient online submission

- thorough peer review by experienced researchers in your field

- rapid publication on acceptance

- support for research data, including large and complex data types

- gold Open Access which fosters wider collaboration and increased citations

- maximum visibility for your research: over $100 \mathrm{M}$ website views per year

At $\mathrm{BMC}$, research is always in progress.

Learn more biomedcentral.com/submissions 